\title{
Successful promotion of physical activity among students of medicine through motivational interview and Web-based intervention
}

\author{
Dubravka Mandic ${ }^{1}$, Vesna Bjegovic-Mikanovic ${ }^{\text {Corresp., } 1}{ }^{1}$, Dejana Vukovic ${ }^{1}$, Bosiljka Djikanovic $^{2}$, Zeljka Stamenkovic $^{2}$, \\ Nebojsa M Lalic ${ }^{3}$ \\ ${ }^{1}$ Centre School of Public Health and Management, Faculty of Medicine, University of Belgrade, Belgrade, Serbia \\ 2 Institute of Social Medicine, Faculty of Medicine, University of Belgrade, Belgrade, Serbia \\ ${ }^{3}$ Clinic for Endocrinology, Diabetes and Metabolic Diseases, Faculty of Medicine, University of Belgrade, Belgrade, Serbia \\ Corresponding Author: Vesna Bjegovic-Mikanovic \\ Email address: vesna.bjegovic-mikanovic@med.bg.ac.rs
}

Background: Regular physical activity supports healthy behavior and contributes to the reduction of preventable diseases. Students in their social transition period are the ideal groups for interventions. The higher education period, associated with demanding changes and poor time management, results in a low level of physical activity. In this age, social media usually are a suitable channel of communication and multicomponent interventions are the most desirable. It has not been sufficiently investigated how effective a Web-based approach is among university students when it comes to physical activity in the long-term period. We combined a Web-based approach with motivational interviews and tested these two interventions together and separate to assess their impact on improving the physical activity of medical students one year after the intervention.

Methods: All 514 first-year students at the Faculty of Medicine in Belgrade were invited to fill in a baseline questionnaire. Also, they underwent measurement of weight, height and waist circumference. After that, students selected a six months intervention according to their preference: Intervention through social media (Facebook) (Group 1) or combined with a motivational interview (Group 2). Group 3 consisted of students without any intervention. One year after completion of the six months intervention period, all students were invited to a second comprehensive assessment. Analyses were performed employing a wide range of statistical testing, including direct logistic regression, to identify determinants of increased physical activity measured by an average change of Metabolic Equivalent of Task (MET). This outcome measure was defined as the difference between the values at baseline and one year after completion of the six months intervention period.

Results: Due to a large number of potential determinants of the change of MET, three logistic regression models considered tri groups of independent variables: basic socio-demographic and anthropometric data, intervention and willingness for change, and health status with life choices. The only significant model comprised parameters related to the interventions $(p<0.001)$. It accurately classified $73.5 \%$ of cases. There is a highly significant overall effect for type of intervention (Wald=19.5, $d f=2, p<0.001$ ) with high odds for the increase of physical activity. Significant relationship between time and type of intervention also existed $(F=7.33, p<0.001$, partial $\eta 2=0.091$ ). The influence of both factors (time and interventions) led to a change (increase) in the dependent variable MET.

Conclusion: Our study confirmed the presence of low-level physical activity among students of medicine and showed that multicomponent interventions have significant potential for positive change. The

Peer) reviewing PDF | (2020:01:44961:2:0:NEW 26 May 2020) 
desirable effects of the Web-based intervention are higher if an additional booster is involved, such as a motivational interview. 
1 Successful promotion of physical activity among students of

2 medicine through motivational interview and Web-based

3 intervention

4 Dubravka Mandic ${ }^{1}$, Vesna Bjegovic-Mikanovic ${ }^{1}$, Dejana Vukovic ${ }^{2}$, Bosiljka Djikanovic ${ }^{2}$, Zeljka

5 Stamenkovic ${ }^{2}$, Nebojsa M. Lalic ${ }^{3}$

$6{ }^{1}$ Centre School of Public Health and Management, Faculty of Medicine, University of Belgrade, Belgrade,

7 Serbia

$8{ }^{2}$ Institute of Social Medicine, Faculty of Medicine, University of Belgrade, Belgrade, Serbia

$9{ }^{3}$ Clinic for Endocrinology, Diabetes and Metabolic Diseases, Faculty of Medicine, University of Belgrade,

10 Belgrade, Serbia

11

12

Corresponding Author:

Vesna Bjegovic-Mikanovic ${ }^{1}$

Dr Subotica 15, Belgrade, 11000, Serbia

16

Email address: vesna.bjegovic-mikanovic@med.bg.ac.rs

\section{Abstract}

Background: Regular physical activity supports healthy behavior and contributes to the reduction of preventable diseases. Students in their social transition period are the ideal groups for interventions. The higher education period, associated with demanding changes and poor time management, results in a low level of physical activity. In this age, social media usually are a suitable channel of communication and multicomponent interventions are the most desirable. It has not been sufficiently investigated how effective a Web-based approach is among university students when it comes to physical activity in the long-term period. We combined a Web-based approach with motivational interviews and tested these two interventions together and separate to assess their impact on improving the physical activity of medical students one year after the intervention.

Methods: All 514 first-year students at the Faculty of Medicine in Belgrade were invited to fill in a baseline questionnaire. Also, they underwent measurement of weight, height and waist circumference. After that, students selected a six months intervention according to their preference: Intervention through social media (Facebook) (Group 1) or combined with a motivational interview (Group 2). Group 3 consisted of students without any intervention. One year after completion of the six months intervention period, all students were invited to a second comprehensive assessment. Analyses were performed employing a wide range of statistical testing, including direct logistic regression, to identify determinants of increased physical activity measured by an average change of Metabolic Equivalent of Task (MET). This outcome 
39 measure was defined as the difference between the values at baseline and one year after 40 completion of the six months intervention period.

41 Results: Due to a large number of potential determinants of the change of MET, three logistic 42 regression models considered tri groups of independent variables: basic socio-demographic and 43 anthropometric data, intervention and willingness for change, and health status with life choices.

44 The only significant model comprised parameters related to the interventions $(\mathrm{p}<0.001)$. It 45 accurately classified $73.5 \%$ of cases. There is a highly significant overall effect for type of 46 intervention (Wald $=19.5, \mathrm{df}=2, \mathrm{p}<0.001$ ) with high odds for the increase of physical activity. 47 Significant relationship between time and type of intervention also existed $(\mathrm{F}=7.33, \mathrm{p}<0.001$, 48 partial $\eta 2=0.091$ ). The influence of both factors (time and interventions) led to a change 49 (increase) in the dependent variable MET.

50 Conclusion: Our study confirmed the presence of low-level physical activity among students of 51 medicine and showed that multicomponent interventions have significant potential for positive 52 change. The desirable effects of the Web-based intervention are higher if an additional booster is 53 involved, such as a motivational interview. 


\section{Introduction}

55 Regular physical activity supports healthy behavior in general and, together with other healthy

56

57

58

59

60

61

62

63

64

65

66

67

68

69

70

71

72

73

74

75

76

77

78

79

80

81

82

83

84

85

86

87

88

89

90

91

92

93 lifestyles, contributes to the reduction of preventable diseases and premature mortality (Blair $\&$ Morris, 2009). On the other hand, physical inactivity is one of the leading risk factors for noncommunicable diseases. According to the most recent estimates, the prevalence of insufficient physical activity is $27.5 \%$ at the global level (Guthold et al., 2018). In 2017, the Institute for Health Metrics and Evaluation (IHME) reported that low physical activity as a global risk factor contributes to ischemic heart disease (in average by $9.1 \%$ ), stroke (by $4.1 \%$ ), and diabetes (by 2.8\%) (IHME, 2017).

There are many arguments to recommend improved physical activity: prevention of cognitive function decline, improvement of musculoskeletal function, and maintaining healthy body weight (Warburton et al., 2006; Reiner et al., 2013; WHO, 2018) but also better feeling in everyday life (Lavie, Ozemek \& Kachur, 2019). The World Health Organization recommends daily moderate physical activity of at least 30 minutes (WHO, 2010), and the American Heart Association has even more precise recommendations (American Heart Association Recommendations for Physical Activity in Adults, 2014).

Young people between 18 and 35 years are one particular segment of the population that is at risk due to lower levels of physical activity and a sedentary lifestyle. This age-group is characterized as a high transition period, when serious changes occur in life: going for higher education, starting a career, and establishing a family. Some authors consider these demanding elements of life as contributing factors in reducing physical activity (Deliens et al., 2015; Aceijas et al., 2017). Notably, the higher education period, associated with growing independence, often results in a change of diet, but also a low level of physical activity (Plotnikoff et al., 2015). The steepest decline in physical activity is seen at the beginning of the university or college period (Kwan et al., 2012; Sigmundova et al., 2013). Some studies suggest that participation in public health interventions is useful and can result in enhanced physical activity and a healthier lifestyle at a later age (Brynteson \& Adams, 1993; Friedman et al., 2008).

According to Plotnikoff, students are the ideal group for interventions fostering an improved lifestyle (Plotnikoff et al., 2015). This population is exposed to a dedicated learning environment and represents a numerically significant proportion of the mature population, surrounded by educators who can help to promote a healthy lifestyle.

The well-known general strategies for behavior change are 1) group interventions, 2) individual interventions, 3) computer-technological interventions, and 4) multicomponent interventions (Rollnick, Miller \& Butler, 2007). The most successful are multicomponent or blended interventions, which combine different strategies (Elvsaas, 2017). Also, programs with pre-arranged frequent contacts are far more successful than interventions offering one contact only (Greaves et al., 2011).

Recently, motivational interviews gained popularity in different settings (Karnes et al., 2015). This technique initially developed to overcome the behavior of addiction (drugs, alcohol), has spread on many fields that require motivation to change behavior (Hettema, Steele \& Miller,

Peer] reviewing PDF | (2020:01:44961:2:0:NEW 26 May 2020) 
94

95

96

97

98

99

100

101

102

103

104

105

106

107

108

109

110

111

112

113

114

115

116

117

118

119

120

121

122

123

124

125

126

127

128

129

130

131

132

133

2005). A 2010 meta-analysis shows that a motivational interview can lead to behavior change in different groups: firefighters, smokers, students, as well as members of different ethnic groups (Lundahl et al., 2010). Also, this approach has been proven to be effective in the improvement of physical activity (Rubak et al., 2005). Motivational interviews raise self-dedication, provide competences, decrease ambivalence, stimulate intrinsic motivation, and increase the possibility of positive change in physical activity. Systematic reviews pointed on the strengths of motivational interviews for empowering and encouraging young people to enhance health behaviors (Mutschler et al., 2018).

Besides the motivational interview, the use of the Internet and Web-based technologies as part of interventions has several advantages: access to a large number of respondents at minimal cost, availability of intervention at any place any time, and the possibility of receiving feedback as well as providing personalized information (Lustria et al., 2013), for a group of young people, the most accessible form of communication (Laranjo et al., 2015; Afshin et al., 2016). One metaanalysis confirmed that internet interventions could lead to significant improvement in health outcomes (Lustria et al., 2013). Some studies suggest that the use of the internet, and primarily Web-based social networks such as Facebook, helps to improve physical activity (Maher et al., 2015; Zhang et al., 2010). Web-based social networks are well accepted in the young generation socialized in the modern environment of the Web and multilateral exchange of experience and worries (Suner, Yilmaz \& Pişkin, 2019). Unlike traditional interventions, online social networks typically achieve high levels of user engagement in physical activity and retention (Davies et al., 2012). The internet use and other accompanying indications request adequate eHealth literacy (Mitsuhashi, 2018) and particularly among young adults. As an example, in the web-based intervention, it may be worthwhile to consider whether the motivational images are expected to increase physical activity or not (Prichard et al., 2020). There is research that shows that sometimes motivational images on social media have the opposite of the intended effect.

However, despite its potential for behavior change and immense popularity, it has not been sufficiently investigated how effective a Web-based approach is among university students when it comes to physical activity (Maher et al., 2014). Notably, students of medicine, due to the timeconsuming curricula, are one of the most sedentary categories among university students (Lee \& Graham, 2001). Additionally, students of medicine are a crucial strategic group because intervening in their early twenties likely will exert a lasting impact on their future careers as medical practitioners, clinicians, or academic teachers and public health promoters.

The objective of this study was to determine the effects of different interventional strategies on improving the physical activity of medical students and to assess predictors of possible improvement. We hypothesized that students exposed to a combined intervention of motivational interview and Web-based intervention during six months would show stronger long-term effects on the physical activity one year later than those exposed to Web-based intervention only or no intervention at all. Also, we expected positive changes in physical parameters, such as body mass index and waist circumference. 


\section{Materials \& Methods}

136

137

138

139

140

141

142

143

144

145

146

147

148

149

150

151

152

153

154

155

156

157

158

159

160

161

162

163

164

165

166

167

168

169

170

171

172

173

\section{Ethical approval}

This study has obtained ethical approval by the Ethical Board of the University of Belgrade, Faculty of Medicine (decision No: 29/IX-7, date: September 19, 2016).

\section{Study Design}

The approach to research was a prospective cohort study among first-year medical students at the Faculty of Medicine, University of Belgrade, before and one year after a six months intervention to improve their physical activity. Also, the approach embraced action research and participation in activities designed to have immediate effects on behavior, changes in lifestyles, and particularly physical activity in the community of first-year students.

\section{Population, recruitment of participants and procedures}

The targeted population presented all first-year students of the Faculty of Medicine, in total 514. We started recruiting students during regular teaching hours at the beginning of the academic year 2016/2017. All students received information (through a flyer or blackboard announcement) about the research topic and were invited to attend a class presenting the research in detail. We obtained the written informed consent from the participants prior to data collection. A total of 254 (49.4\%) students filled in correctly both the informed consent template and a baseline questionnaire (see annex 1), provided contact details and underwent measurement of weight, height and waist circumference. Completing the questionnaire was voluntary, anonymous and without incentives. The students were then invited to enter a self-selected six months intervention according to their preference, either Web-based intervention through Facebook only (Group 1) or combined intervention with a motivational interview and Web-based intervention through Facebook (Group 2): 86 students chose Group 1, and 37 students selected Group 2. Students who were not interested in joining the intervention formed Group 3, consisting of 131 students. Figure 1 presents the flowchart of participants' recruitment and retention. We did not form a group with the motivational interview alone: a) because of the limited number of participants, and b) because our research question was to see whether the common Web-based intervention can be improved by motivational interviews.

Here Figure 1 Participants' flowchart - recruitment, choice of intervention group and retention

After one year from completion of the six months intervention, all students were invited to a second assessment. In Group 1, the response rate was $70.9 \%$, and in Group $2100 \%$, while among those who were not interested in joining any intervention (Group 3), the response rate was $57.3 \%$. We choose this extended period to be sure about a long-term impact on lifestyle. 


\section{Research instruments}

175 At baseline, the students filled in the questionnaire designed to create a physical activity profile

176

177

178

179

180

181

182

183

184

185

186

187

188

189

190

191

192

193

194

195

196

197

198

199

200

201

202

203

204

205

206

207

208

209

210

211 with a provision of personalized feedback. Before the main research, a pre-test and a series of focus groups, including 15 medical students, each served to determine the feasibility of the research in terms of the amount and quality of data to be collected. Students gave feedback about the content of the questionnaire, the relevance of the questions, and its length. Based on their opinions and recommendations, the final version of the questionnaire was optimized.

The questionnaire contained the following sections: [1] socio-demographics, anthropometric data, and self-rated health; [2] the current level of physical activity; [3] the preferred type of physical activity; [4] multidimensional well-being; [5] mental health; and [6] lifestyle. The completion of the questionnaire (annex 1) took approximately 30 minutes. An introductory page presented the study. It contained information about the research goals and the secret identification code that was used to match data from the first and second waves of this study.

Within the socio-demographics, we included: gender, age, nationality, type of transportation to the Faculty, time to get to the Faculty, academic achievements (average mark), height, weight, waist circumference, relationship status, and household income per capita. The majority of the items in this section were drawn from the European Health Interview Survey wave 2 (EHIS wave 2) (Eurostat, 2013). The anthropometric data were assessed in a separate room with the help of at least one medical doctor to be as precise as possible.

Physical activity (PA) was examined at baseline through the International Physical Activity Questionnaire - Short Version (IPAQ-SV) (Craig et al., 2003). The data was then used to estimate total weekly physical activity by weighting the reported minutes per week within each activity category by a Metabolic Equivalent of Task (MET) energy expenditure estimate assigned to each category of activity. The weighted MET-minutes per week were calculated as duration of activity multiplied by frequency per week multiplied by 8 for vigorous-intensity PA, by 4 for moderateintensity, and by 3.3 for walking level. The total number of MET-minutes per week was obtained by summing up the subtotals. This value was selected as the dependent variable. The section about physical activity also presented sub-sections with consideration of the actual level of physical activity, satisfaction with the level of physical activity, reasons for inactivity, wish to improve physical activity. In case the respondent expressed a wish to be more active, the following page included a modified version of the IPAQ-SV. The result of this IPAQ-SV was the total number of wished MET-minutes per week.

The next section included two items regarding the preferred type of physical activity and the type of physical activity to be improved in the next month. Both items present the same options, with the possibility to select more answers: walking/hiking, running/jogging, individual gym workout, group gym workout, indoor/outdoor group sports, water sports, and winter sports, dance, other-specify. 
212 The next section included items regarding mental health, and it contains an 8-items 213 measure of depression symptoms from the Physical Health Questionnaire - 8 (PHQ-8) (Kroenke 214 et al., 2009; McMahon et al., 2017).

215 The last set of questions was about self-rated health and life choices, and it included:

216 smoking cigarettes, cannabis/marijuana consumption, binge drinking, and intakes of fruit and 217 vegetable.

218

219 Intervention for improvement of physical activity

After completing the baseline study, the participants were invited to join a specially created

221 Web-based project group through Facebook. The project group aimed to continuously promote

222 healthy lifestyles and motivate students to engage in physical activity by sharing various

223 appropriate content based on similar interventions (Bonnie, Stroud \& Breiner, 2014).

The Web-based (WB) intervention in both groups (Group 1 and 2) was "closed," allowing

224

225

226 only participants enrolled in the study to view the posted information and the profiles of other participants who are members of the group. The Web-based intervention in each group (1 and 2) had three administrators (public health experts). Their tasks were to post and possibly moderate the comment section for each intervention content, referring to certain common physical activities - events such as participation in the Marathon in Belgrade; regularly check the main Facebook page of the group, to decide whether the content that the students have set up desirably represents the group; and remove or prohibit group members showing offensive behavior. The Web-based intervention had three components designed to increase physical activity, and included:

1) Scientific publications regarding physical activity promotion posted on the group Facebook wall (once a week, in total 24 articles selected by administrators); these works highlighted the low physical activity levels of the student population, with the associated disease burden, and addressed prevalent socio-cultural norms and barriers to physical activity commonly reported among students;

2) Questions leading to a discussion on topics related to physical activity and participant engagement (once a week, in total 24 questions opening discussions in which each student from Group 1 and 2 has an opportunity to participate and express opinions); the purpose of the weekly discussion topics was sharing of personal experiences with physical activity and giving/receiving social support for physical activity (e.g., "What are your thoughts on the physical activity statistics among students? How can you incorporate more physical activity into your daily routine?");

3) Motivational text messages and images promoting physical activity (three times a week, in total 72 posts); these text messages acted as another mechanism of social support and provided: (a) tips on strategies to increase physical activity throughout the day (e.g., "Set aside time today for several 10-15-minute walks. Walking 30 minutes at a moderate-intensity on 5 days each week = 150 minutes!'), (b) information on how to overcome barriers to physical activity (e.g., "Don't let the lack of time interfere with your physical activity routine. Take a 
252 walk with your whole family this weekend".), (c) reminders on the health benefits of physical

253 activity (e.g., "Physical activity promotes health and reduces the risk of bone fractures and 254 osteoporosis."), and (d) motivational/inspirational tips and quotes to participants (e.g., " "Each 255 person must live their life as a model to others'. - Rosa Parks").

256 The aim of this closed discussion via Facebook was to motivate mutually by the exchange 257 of positive experiences and intentions to improve physical activity.

258 Students additionally got an opportunity to apply for a motivational interview, and 37 259 students accepted. Therefore they formed a Group 2 exposed both to Web-based intervention and 260 motivational interview. Motivational interviews were done using Motivational Interviewing 261 techniques (Miller \& Rollnick, 2013.). Individual consulting within a motivational interview was 262 a voluntary activity, and its content is treated as confidential and anonymous. The interviewers 263 were health workers who were trained by a certified trainer for motivational interviewing (MINT, 264 2016). Motivational interviews were conducted at a time agreed with a certified teacher, in an 265 area that can provide undisturbed individual work. Each student attended two face-to-face 266 sessions at the beginning of the intervention, individually tailored, with a duration of 45 minutes each. The content and the spirit of the sessions are presented in the Protocol for Motivational Interview (see annex 2). The second session followed after 14 days and served as self-reflection on the feedback for the physical activity, geared towards strengthening commitment to make a positive change.

\section{Statistical analysis}

The variables in this study are presented as continuous data (scale) or categorical (nominal and ordinal). Continuous data are summarized as mean value with standard deviation and $95 \% \mathrm{CI}$ or for skewed data as median with interquartile range (IQR). Categorical data are provided by their absolute numbers and percentages. In the analysis Chi-square test, Student's t-test for independent or paired samples, Mann-Whitney test (not Gaussian distribution), Kruskal-Wallis test, Fisher's Exact test (when necessary, in the case of low frequencies), Wilcoxon signed ranks test, ANOVA and post hoc analysis, and binary logistic regression (Enter model) were used. The alpha level at 0.05 ( $\mathrm{p}$ value $<0.05$ ) was considered to indicate significance. Levene's test was employed to assume the Equality of Variances. The normal distribution of each variable was to be checked with the Kolmogorov-Smirnoff test. To perform mixed-design analysis of variance (ANOVA) for repeated measurements, a logarithmic transformation of data for MET was performed to achieve normal distribution of samples in all (three) examined groups for both measurement times (baseline and after 12 months). Atypical outliers were eliminated, and the selected significance level was set to $\alpha=0,01$.

\section{Results}

The descriptive variables of the study participants are presented in Table 1. At the end of the intervention period, in total, 173 medical students remained in the three groups. The first group 
292 of "Web-based intervention only" had 61 students, the second group with both "Motivational 293 Interview and Web-based intervention" - 37 and the group without intervention comprised 75 294 students (see figure 1). There was no significant difference between the three groups at the 295 baseline assessment.

296 Students' average age was 20.34 years (SD 0.57), among which 51 (29.5\%) were male, 297 while almost two-thirds of them were female 122 (70.5\%). Their average academic achievement 298 was 8.704 (SD 0.80) out of 10. Results are showing that the majority of them are using public 299 transport, while only $17.3 \%$ are walking to the faculty. Bicycles and cars were only marginal 300 choices. Participants reported that the usual time to get to the faculty was 25 minutes. On 301 average, household income per capita per month was $300 €$, while only $12.1 \%$ of students 302 303 reported more than $600 €$.

\section{Here Table 1 Characteristics of study participants at baseline}

Health status and life choices are presented in Table 2. Overall, most of the students estimated their health as very good $(81 / 46.8 \%)$ and good $(68 / 39.3 \%)$, while $22(12.7 \%)$ rated their health as average. The majority of students had good mental health, with a PHQ-8 score below 10. Students had an average BMI of $21.62 \mathrm{~kg} / \mathrm{m} 2$ with SD 2.75, being in a range of normal weight. Average waist circumference was normal, for both male and female group of students. The results related to smoking were: $15.6 \%$ of students declared actual smoking of cigarettes, and 5.2\% used cannabis/marijuana in the year preceding the study. Half of the students (50.3\%) reported binge drinking (6 or more drinks on one occasion) during the year before the study. In terms of healthy eating habits, daily intake of fruit and vegetable was adequate only for one-third of the participants. There was no significant difference in examined parameters between groups.

\section{Here Table 2 Health status and life-choices of medical students at baseline}

\section{Comparison of physical activity calculated in average MET (Table 3) 12 months after the} intervention period has shown a significant difference between both groups with the intervention compared to Group 3 without any intervention $(\mathrm{p}<0.001)$ (Kruskal Wallis test). Level of physical activity, measured in median MET (IQR) has increased from 1506 (2058) to 2813 (1680) $(\mathrm{p}<0.001)$ in Group 1 exposed only to Web-based intervention, and from 1386 (1579) to 2586 (1794) $(\mathrm{p}<0.001)$ in Group 2 exposed to both Web intervention and motivational interview. At the same time, in Group 3, without intervention, starting from baseline median MET (IQR) of 1155 (1053), physical activity has been slightly increased. However, this change is not significant, as shown in Table 3.

Here Table 3 The physical activity and related variables before and after the intervention 
332

333

334

335

336

337

338

339

340

341

342

343

344

345

346

347

348

349

350

351

352

353

354

355

356

357

358

359

360

361

362

363

364

365

366

367

368

369

370

371

Most of the examined participants were not satisfied at the beginning of the study with the level of their physical activity, without significant difference between the groups. The level of satisfaction did not significantly increase 12 months after intervention $(p=0.287)$ for any of the three groups. The main reason leading to physical inactivity was the lack of time for all participants, without significant difference between the groups. Then tiredness and unwillingness followed as reasons. We did not find any significant difference between groups, except for one reason, "no wish for physical activity," which was the most present in Group 2 ( $p=0.012$ ). In terms of the type of preferred activity, there is a significant difference $(p=0.023)$ between all three groups for walking after the intervention. The highest percentage of students who prefer walking after 12 months was in Group 2. A wish for physical activity is present at the beginning of the study period for most of the participants, without significant difference, both at baseline and 12 months after the intervention. However, the biggest percentage of those who wished to be physically active, after 12 months, is found in Group 2.

\section{Predictors of students' physical activities - regression models}

Direct logistic regression (Table 4) was conducted to evaluate the impact of multiple factors on the probability of increasing physical activity, measured in an average change of MET. The change of MET was defined as the positive difference between the values for baseline (BL) and after 12 months (12M). Due to a large number of factors that could affect the dependent variable (change of MET), they were grouped in three models: basic socio-demographic and anthropometric data, intervention and willingness for change, and health status with life choices.

The only significant model was with intervention and willingness for change as factors that could affect the change of MET (Table 4). The second model contained, as independent variables, parameters related to physical activity intervention: belonging to one of three groups (Web-based intervention only, motivational interview and Web-based intervention, and without intervention), the total number of reasons for inactivity, the total number of preferred activities, planned activities, wish for physical activity and satisfaction with physical activity. The whole model is statistically significant ( $\mathrm{hi} 2=32.7, \mathrm{df}=7, \mathrm{n}=170, \mathrm{p}<0.001$ ). The model explains between 17.5\% Cox and Snells R-squared and 24.5\% Nagelkerkes R-squared and accurately classifies $73.5 \%$ of cases. The sensitivity of the model is $86.2 \%$, and the specificity is $46.3 \%$. The positive predictive value is $77.5 \%$.

There is a highly significant overall effect for type of intervention (Wald $=19.5, \mathrm{df}=2$, $\mathrm{p}<0.001$ ) with high odds for the increase of physical activity. Students in Group 2, "Motivational interview and Web-based intervention," are 3.25 times more likely than those from Group 1 "Only Web-based intervention" (reference category) to increase physical activity. This trend was not statistically significant, but students "without intervention" are 0.26 times less likely to increase physical activity, significantly different before and after controlling for other examined parameters related to physical activity. The students with a higher number of reasons for inactivity at baseline are two times more likely to improve physical activity as well. 
372 Here Table 4 Logistic regression identifying associations between physical activity with the type 373 of intervention and other physical activity-related variables

374

375

376

377

378

379

380

381

382

383

384

385

386

387

388

389

390

391

392

393

394

395

396

397

398

399

400

401

402

403

404

405

406

407

408

409

410

411

Mixed ANOVA model for measurement times (baseline and after 12 months) found that there was a significant main effect for the three groups $(\mathrm{F}=16.41, \mathrm{p}<0.001)$ on the dependent variable MET, with a measure of the relatedness of $18.2 \%$ (partial $\eta 2$ (Eta-squared) $=0,182$ ). There was a significant general difference in MET values between the groups.

By comparing the pairs of groups via the Turkay HSD test, with the Bonferoni correction, it was found that there was a significant difference in MET change between the groups "Only WB intervention" (mean $(\mathrm{M})=7.60$ and "without the intervention" $\mathrm{M}=7.15, \mathrm{p}<0.001$ ) (mean difference $=0.458,95 \%$ CI: 0.252-0.663) and the "motivational interview and WB" group (M= 7.52 ) and "without the intervention" $(\mathrm{M}=7.15), \mathrm{p}<0.001$ (mean difference $=0.371,95 \% \mathrm{CI}$ : $0.145-0.597)$.

Also, the independent variable "time" presented a significant main effect $(\mathrm{F}=42.73, \mathrm{p}$ $<0.001$, par. $\mathrm{H} 2=0.225)$. MET values were significantly lower before $(\mathrm{M}=7.214)$ than after 12 months $(\mathrm{M}=7.629)$ of intervention.

Significant relationship between time and type of intervention also existed $(F=7.33, p$ $<0.001$, partial $\eta 2=0.091$ ). Figure 2 presents the estimated marginal means of MET before and after the intervention. A comparison of the mean values of MET by groups at two times shows the increase of MET in the first two groups but not in the group "without the intervention." The influence of both factors (time and interventions) led to a change (increase) in the dependent variable MET. The significance of the interaction of these two factors shows that one variable depends on the level of the other.

Here Figure 2 Estimated marginal means of MET before and after the intervention

\section{Discussion}

The present study examined the success of physical activity promotion among students of medicine through motivational interview and Web-based intervention, which lasted for six months. Our study had three groups: Group 1 exposed to Web-based intervention, Group 2 combined intervention with a Motivational Interview and Web-based intervention, and Group 3 stayed without intervention. Comparison of physical activity calculated in average MET, before and 12 months after the intervention of 6 months, has shown a significant difference between the two groups with the intervention compared to the third group without intervention. Furthermore, our study has pointed out that motivational interview can boost the positive change in physical activity occurring among students exposed to social media intervention. We did not obtain any significant predictors of physical activity improvement assessed by direct logistic regression, except the participation in the intervention and number of reasons given for physical inactivity at baseline. 
413 Unmet needs of students call for improvement of physical activity and well being

414 Our study provides evidence of various unmet needs of university students in terms of their

415 lifestyle, and those results could be a cause for concern for the future trend of chronic diseases

416 among this group. Overall, only $17.3 \%$ of examined students were walking to the faculty, while

417 the majority were using public transport. Almost $16 \%$ of the students were smoking cigarettes.

418 This finding is in line with previously published studies in other countries (Aceijas et al., 2017,

419 Thomas et al., 2019, Wamamili et al., 2019).

420 Regarding marijuana, $5.2 \%$ of students were consumers, slightly lower than in comparable

421 studies (Suerken et al., 2016; Ayala et al., 2017; Candido et al., 2018). Overall, even half of the

422 students reported binge drinking. Those findings are consistent with some other studies regarding

423 alcohol misuse (Beenstock et al., 2010), where college years were already identified as a risk

424 period to develop substance use disorders (Larimer et al., 2005).

425 Only one-third of the examined students had healthy eating habits, measured as daily

426 intake of fruit and vegetable. Our findings are consistent with previous studies identifying

427 outcomes of compromised dietary balance. In a study from four European countries, only 15-

$42832 \%$ of university students reported daily vegetable intake. In contrast, for the same group, daily

429 fruit consumption was found in less than $50 \%$, which is still much higher compared to our study

430 (El Ansari et al., 2012). Numerous studies have shown a low prevalence of fruit and vegetable 431 intake by undergraduates (Cook et al., 2014; Farias et al., 2014).

432 Regular physical activity during the time of the transition from youth to adulthood is an 433 essential base for adult life patterns (Telama et al., 2014). However, at the beginning of our 434 study, the level of physical activity was low among all groups of students, and most of them 435 were not satisfied with such performance. This result is in line with the finding that levels of 436 physical activity among students are not sufficient (Marques et al., 2016). Though physical 437 activity improved after 12 months among students exposed to the intervention, the level of 438 satisfaction with physical activity did not significantly change for neither of the groups.

439

440

441

442

443

444

445

446

447

448

449

450

451

452

\section{Reasons for the low level of physical activity and possible factors for improvement}

The main reason leading to physical inactivity in our study was lack of time. This finding is in line with a similar result of a study conducted among female medical students where the most critical barrier to exercise was also lack of time (Majeed, 2015) and in line with a study from 2019 (Thomas et al., 2019). Also, some qualitative studies with focus groups revealed that lack of time is a common if not the most common reason for physical inactivity among students (Greaney et al., 2009; Nelson et al., 2009, Ranasinghe et al, 2016) which was confirmed in the recently published study among the university students (Oluyinka \&Endozo, 2019).

After 12 months after the intervention period, we found that „lack of time“ remained the main reason for a low level of physical activity for all participants, even those included in the intervention.

During years at college, students are facing plenty of distractions, especially those living not at home with their families. An important skill, which needs practice, is time management. 
453 Without time management, students may find themselves behind on their studies, experiencing 454 mental and emotional stress, or even at the risk of failing. Even though students of higher grades 455 do report significantly better time-management skills than first- and second-year students

456 (Trueman \&Hartley, 1996), universities could actively try to improve basic time management 457 strategies so that learners can improve their overall learning experience and can allocate time to 458 physical activity.

459 Other factors mentioned in the literature, which can stimulate physical activity among 460 students, are: well- being, fun and pleasure, contact with others, and health (Diehl et al., 2018). 461 On the other side, university students with high sedentary behavior and students who spent more 462 than 7 hours per week studying are more likely to be physically inactive. One study has shown a 463 significant difference in terms of gender were women had a higher chance of being physically 464 low active (Concha-Cisternas et al., 2018). This result was not found in our study, as we did not 465 obtain any significant predictors of physical activity improvement assessed by direct logistic 466 regression, except the participation in the intervention and number of reasons for physical 467 inactivity.

\section{Preferred physical activity}

In terms of the type of preferred activity, there is a significant difference $(\mathrm{p}=0.023)$ among all three groups after the intervention: walking was the preferred activity in all groups. The most significant number of students who prefer walking after 12 months was in Group 2 - exposed to both Motivational Interview and Web-based intervention, where $86.5 \%$ of students appreciated the option to walk. Those students under our intervention were much more interested in walking compared to other studies (Majeed, 2015; Doyle, Khan \& Burton, 2019).

The particular group, i.e., medical students, could be especially interesting, as those current university students in the future probably can play an essential role as opinion leaders in establishing norms of life for the general public and their patients (Leslie et al., 1999; Sehgal, 2018).

A comparison of the mean values of MET by groups at two times shows the increase of MET in the first two groups but not in the group "without intervention." The influence of both factors (time and interventions) led to a change (increase) of dependent variable MET. The significance of the interaction of these two factors shows that one variable depends on the level of the other. This result means that we were able to increase the frequency and intensity of physical activity in both groups under intervention.

\section{Strengths and weaknesses of the study}

The advantage of this study is the cohort design, where both the motivational interview and webbased intervention were used to improve physical activity among university medical students. Second, the group of students of medicine is particularly interesting as, in the future, their role will be to promote a healthy lifestyle to the population. Third, the strength of our study is the examination of a wide variety of possible predictors of physical activity, which were used in the 
493 logistic models, allowing us to detect significant determinants. However, some limitations should 494 be acknowledged.

495 First, the groups who accepted to participate in the study were formed based on the 496 students' choices. The rationale behind this design is to overcome situational bias and possibly 497 drop out as the participants' reaction to the assigned vs. voluntarily chosen intervention. We 498 intended to introduce as many students as possible in the intervention, ensuring sufficient power

499

500

501

502

503

504

505

506

507

508

509

510

511

512

513

514

515

516

517

518

519

520

521

522

523

524

525

526

527

528

529

530

531

532

to detect effects if they existed. Therefore, we have chosen approach of voluntary involvement as we did have many proofs that this group of participants is reporting lack of time as the main reason for physical inactivity, which can cause significant drop out from the intervention (Majeed, 2015; Thomas et al., 2019; Greaney et al., 2009; Nelson et al., 2009, Ranasinghe et al., 2016; Oluyinka \& Endozo, 2019). At the same time, there was a need to include psychological variables such as readiness to change and self-efficacy related to physical activity. Those variables can influence the interpretation of intervention impact within the groups, and they can serve for understanding mechanisms by which intervention is likely to impact physical activity (Shaver et al., 2019; Bezner et al., 2018; Karnes et al., 2015). Considering all mentioned, it is important to say that for all characteristics observed, we did not find any significant difference between three groups (two with intervention and one without) at the beginning of the study. Second, the response rate 12 months after the intervention should have been higher. Third, selfassessment often can differ from the real status: in the case of physical activity, physiological indicators could confirm or disconfirm the result of the IPAQ questionnaire (Lyden et al., 2017). Fourth, most included predictors primarily focused on physical activity and not specifically on sedentary behaviors.

Based on the finding of the study, but also the listed limitations, we can formulate some suggestions for research in the future. First, to ensure a better response rate with a different approach to the examined group. Second, it would be recommendable to include physiological indicators obtained by real-time measurement of physical activity such as with activPAL TM instead of self-assessment done by the IPAQ questionnaire. Third, assessing stages of change, processes of change, self-efficacy, and decisional balance would be highly recommended for future studies to ensure that all aspects of the possible impact on physical activity improvement are covered. Nevertheless, our study pointed to the relevance of timely interventions for the successful promotion of physical activity among students.

\section{Conclusions}

The study confirmed the presence of low-level physical activity among students of medicine measured by MET and possible options for its improvement based on intervention. Despite expectations, socio-demographic characteristics and life choices were not related to positive changes, but the change happened under intervention. Our study showed that interventions for improvement of physical activity among students have significant potential. Though previous studies found evidence that Web-based intervention through Facebook is beneficial for positive

Peer) reviewing PDF | (2020:01:44961:2:0:NEW 26 May 2020) 
533 changes of MET, we confirmed that the involvement of combined interventions could bring 534 better results. The desirable effects of the intervention are higher if an additional booster is 535 involved, such as a motivational interview. Taking into account that such interventions are more 536 expensive and less accessible for the average young population, the future steps will be to assess 537 their cost-effectiveness.

538

539

540

541

542

543

544

545

546

547

548

549

550

551

552

553

554

555

556

557

558

559

560

561

562

563

564

565

566

567

568

569

570

571

572

\section{Acknowledgements}

We would like to thank all students of the Faculty of Medicine who participated in the intervention study. We would also like to thank the staff of the Institute of Social Medicine (Faculty of Medicine, University of Belgrade) for their commitment to performing motivational interviews with students.

\section{References}

Aceijas C, Waldhäusl S, Lambert N, Cassar S, Bello-Corassa R. 2017. Determinants of health-related lifestyles among university students. Perspectives in Public Health 137(4):227-236 DOI 10.1177/1757913916666875.

Afshin A, Babalola D, Mclean M, Yu Z, Ma W, Chen CY, Arabi M, Mozaffarian D. 2016. Information Technology and Lifestyle: A Systematic Evaluation of Internet and Mobile Interventions for Improving Diet, Physical Activity, Obesity, Tobacco, and Alcohol Use. Journal of the American Heart Association 5(9):e003058 DOI 10.1161/JAHA.115.003058.

American Heart Association Recommendations for Physical Activity in Adults. 2014. Available at https://www.heart.org/en/healthy-living/fitness/fitness-basics/aha-recs-forphysical-activity-in-adults (accessed 25 May 2020).

Ayala EE, Roseman D, Winseman JS, Mason HRC. 2017. Prevalence, perceptions, and consequences of substance use in medical students. Medical Education Online 22(1): 1392824 DOI 10.1080/10872981.2017.1392824.

Beenstock J, Adams J, White M. 2011. The association between time perspective and alcohol consumption in university students: cross-sectional study. European Journal of Public Health 21(4):438-443 DOI 10.1093/eurpub/ckp225.

Bezner JR, Franklin KA, Lloyd LK, Crixell SH. 2018. Effect of group health behaviour change coaching on psychosocial constructs associated with physical activity among university employees. International Journal of Sport and Exercise Psychology 18(1):93107 DOI: 10.1080/1612197X.2018.1462232.

Blair SN, Morris JN. 2009. Healthy hearts--and the universal benefits of being physically active: physical activity and health. Annals of Epidemiology (19)4:253-256 DOI 10.1016/j.annepidem.2009.01.019.

Bonnie R, Stroud C, Breiner H. 2014. Investing in the health and well-being of young adults. Washington DC: The National Academies Press. 
573 Brynteson P, Adams TM. 1993. The effects of conceptually based physical education programs

574

575

576

577

578

579

580

581

582

583

584

585

586

587

588

589

590

591

592

593

594

595

596

597

598

599

600

601

602

603

604

605

606

607

608

609

610

611

612

613

614

615

616 on attitudes and exercise habits of college alumni after 2 to 11 years of follow-up. Res $Q$ Exerc Sport 64(2):208-212 DOI 10.1080/02701367.1993.10608798.

Candido FJ, Souza R, Stumpf MA, Fernandes LG, Veiga R, Santin M, Kluthcovsky A. 2018. The use of drugs and medical students: a literature review. Revista da Associação Médica Brasileira 64(5):462-468 DOI 10.1590/1806-9282.64.05.462.

Concha-Cisternas Y, Guzmán-Muñoz E, Valdés-Badilla P, Lira-Cea C, Petermann F, Celis-Morales C. 2018. Levels of physical activity and excess body weight in university students. Revista médica de Chilee 146(8):840-849 DOI 10.4067/s003498872018000800840.

Cooke R; Papadaki A. 2014. Nutrition Label Use Mediates the Positive Relationship between Nutrition Knowledge and Attitudes towards Healthy Eating with Dietary Quality among University Students in the UK. Appetite 83:297-303 DOI 10.1016/j.appet.2014.08.039.

Craig CL, Marshall AL, Sjöström M, Bauman AE, Booth ML, Ainsworth BE, Pratt M, Ekelund U, Yngve A, Sallis JF, Oja P. 2003.: International Physical Activity Questionnaire: 12-country reliability and validity. Medicine and Science in Sports and Exercise 35(8):1381-1395 DOI 10.1249/01.MSS.0000078924.61453.FB.

Davies CA, Spence JC, Vandelanotte C, Caperchione CM, Mummery WK. 2012. Metaanalysis of Internet-delivered interventions to increase physical activity levels. Int J Behav Nutr Phys Act 9:52 DOI 10.1186/1479-5868-9-52.

Deliens T, Deforche B, De Bourdeaudhuij I, Clarys P. 2015. Determinants of physical activity and sedentary behaviour in university students: a qualitative study using focus group discussions. BMC Public Health 15:201 DOI 10.1186/s12889-015-1553-4.

Diehl K, Fuchs AK, Rathmann K, Hilger-Kolb J. 2018. Students' Motivation for Sport Activity and Participation in University Sports: A Mixed-Methods Study. Biomed Research International 2018:9524861 DOI 10.1155/2018/9524861.

Doyle CB, Khan A, Burton NW. 2019. Recreational physical activity context and type preferences among male and female Emirati university students. International Health 11 (6):507-512 DOI 10.1093/inthealth/ihz002.

El Ansari W, Stock C, Mikolajczyk RT. 2012. Relationships between food consumption and living arrangements among university students in four European countries - a crosssectional study. Nutritional Journal 11:28 DOI 10.1186/1475-2891-11-28.

Elvsaas KØ, Giske L, Fure B, Juvet, LK. 2017. Multicomponent Lifestyle Interventions for Treating Overweight and Obesity in Children and Adolescents: A Systematic Review and Meta-Analyses. Journal of Obesity 2017:5021902 DOI https://doi.org/10.1155/2017/5021902.

Eurostat. 2013. European Health Interview Survey (EHIS wave 2)-Methodological manual. Luxembourg: European Commission.

Farias SC, de Castro IRR, da Matta VM, Castro LMC. 2014. Impact Assessment of an Intervention on the Consumption of Fruits and Vegetables by Students and Teachers. Revista de Nutrição 27(1):55-65 DOI 10.1590/1415-52732014000100006.

Friedman HS, Martin LR, Tucker JS, Criqui MH, Kern ML, Reynolds CA. 2008. Stability of physical activity across the lifespan. Journal of Health Psychology 13(8):1092-1104 DOI 10.1177/1359105308095963. 
617 Greaney ML, Less FD, White AA, Dayton SF, Riebe D, Blissmer B, Shoff S, Walsh JR,

618 Greene GW. 2009. College Students' barriers and enablers for healthful weight

619

620

621 management: a qualitative study. Journal of Nutrition Education and Behaviour 41(4):281286 DOI 10.1016/j.jneb.2008.04.354.

Greaves CJ, Sheppard KE, Abraham C, Hardeman W, Roden M, Evans PH, Schwarz P,

622 The IMAGE Study Group. 2011. Systematic review of reviews of intervention

623 components associated with increased effectiveness in dietary and physical activity

624

625 interventions. BMC Public Health 11:119 DOI 10.1186/1471-2458-11-119.

Guthold R, Stevens GA, Riley LM, Bull FC. 2018. Worldwide trends in insufficient physical activity from 2001 to 2016: A pooled analysis of 358 population-based surveys with 1.9

627 million participants. The Lancet Global Health 6(10):1077-1086 DOI 10.1016/S2214-

628

629 109X(18)30357-7.

Hettema J, Steele J, Miller WR. 2005. Motivational interviewing. Annual Review of Clinical Psychology 1:91-111 DOI 10.1146/annurev.clinpsy.1.102803.143833.

630

631

632

633

634

635

636

637

638

639

640

641

642

643

644

645

646

647

648

649

Institute for Health Metrics and Evaluation (IHME). 2017. Findings from the Global Burden of Disease Study. Seattle, WA: IHME.

International Physical Activity Questionnaire. Available at https://sites.google.com/site/theipaq/(accessed 25 May 2020).

Karnes SL, Meyer BB, Berger LM, Brondino MJ. 2015. Changes in Physical Activity and Psychological Variables Following a Web-Based Motivational Interviewing Intervention: Pilot Study. JMIR Research Protocols 4(4):e129 DOI 10.2196/resprot.4623.

Kroenke K, Strine TW, Spitzer RL, Williams JB, Berry JT, Mokdad AH. 2009. The PHQ-8 as a measure of current depression in the general population. Journal of Affective Disorders 114(1-3):163-173 DOI 10.1016/j.jad.2008.06.026.

Kwan MY, Cairney J, Faulkner GE, Pullenavegum EE. 2012. Physical activity and other health-risk behaviours during the transition into adulthood: A longitudinal cohort study, American Journal of Preventive Medicine 42(1):14-20 DOI 10.1016/j.amepre.2011.08.026.

Laranjo L, Arguel A, Neves AL, Gallagher AM, Kaplan R, Mortimer N, Mendes GA, Lau AY. 2015. The influence of social networking sites on health behavior change: a systematic review and meta-analysis Journal of the American Medical Informatics Association 22(1):243 DOI 10.1136/amiajnl-2014-002841.

Lavie CM, Ozemek C, Kachur S. 2019. Promoting physical activity in primary and secondary prevention. European Heart Journal 40(43):3556-3558 DOI 10.1093/eurheartj/ehz697.

651

Lee J, Graham AV. 2001. Students' perception of medical school stress and their evaluation of

652

653 a wellness elective. Medical Education 35(7):652-659 DOI 10.1046/j.13652923.2001.00956.x.

654

655

Leslie E, Owen N, Salmon J, Bauman A, Sallis JF, Lo SK. 1999. Insufficiently active Australian college students: perceived personal, social, and environmental influences.

656

657

658

Preventive Medicine 28 (1):20-27 DOI 10.1006/pmed.1998.0375.

Lundahl BW, Kunz C, Brownell C, Tollefson D, Burke BL. 2010 A meta-analysis of motivational interviewing: twenty-five years of empirical studies. Research on Social Work 659 Practice 20(2):137-160 DOI 10.1177/1049731509347850. 
660

661

662

663

664

665

666

667

668

669

670

671

672

673

674

675

676

677

678

679

680

681

682

683

684

685

686

687

688

689

690

691

692

693

694

695

696

697

698

699

700

701

702

703

Lustria ML, Noar SM, Cortese J, Van Stee SK, Glueckauf RL, Lee J. 2013. A MetaAnalysis of Web-Delivered Tailored Health Behavior Change Interventions. Journal of Health Communication 18(9):1039-1069 DOI 10.1080/10810730.2013.768727.

Lyden K, Keadle SK, Staudenmayer J, Freedson PS. 2017. The activPALTM Accurately Classifies Activity Intensity Categories in Healthy Adults. Medicine \& Science in Sports \& Exercise 49(5):1022-1028 DOI 10.1249/MSS.0000000000001177.

Maher CA, Lewis LK, Ferrar K, Marshall S, De Bourdeaudhuij I, Vandelanotte C. 2014. Are health behavior change interventions that use online social networks effective? A systematic review. Journal of Medical Internet Research 16(2):e40 DOI 10.2196/jmir.2952.

Maher C, Ferguson M, Vandelanotte C, Plotnikoff R, De Bourdeaudhuij I, Thomas S, Nelson-Field K, Olds T. 2015. A web-based, social networking physical activity intervention for insufficiently active adults delivered via Facebook app: randomized controlled trial. Journal of Medical Internet Research 17(7):e174 DOI 10.2196/jmir.4086.

Majeed F. 2015. Association of BMI with diet and physical activity of female medical students at the University of Dammam, Kingdom of Saudi Arabia. Journal of Taibah University Medical Sciences 10(2):188-196 DOI 10.1016/j.jtumed.2014.11.004.

Marques A, Martins J, Peralta M, Catunda R, Nunes LS. 2016. European adults' physical activity socio-demographic correlates: a cross-sectional study from the European Social Survey. PeerJ 4:e2066 DOI 10.7717/peerj.2066.

McMahon AB, Arms-Chavez CJ, Harper BD, LoBello SG. 2017. PHQ-8 minor depression among pregnant women: association with somatic symptoms of depression. Archives of Womens Mental Health 20(3):405-409 DOI 10.1007/s00737-017-0715-z.

Miller, WR, Rollnick, S. 2013. Motivational interviewing: helping people change. New York, NY: Guilford Press.

MINT (Motivational Interviewing Network of Trainers). 2016. List of certified trainers. Available at https://motivationalinterviewing.org/profile/stijnvanmerendonk (accessed 24 May 2020).

Mitsuhashi T. 2018. Effects of two-week e-learning on eHealth literacy: a randomized controlled trial of Japanese Internet users. PeerJ 6:e5251 DOI 10.7717/peerj.5251.

Mutschler C, Naccarato E, Rouse J, Davey C, McShane K. 2018. Realist-informed review of motivational interviewing for adolescent health behaviors. Syst Rev 7(1):109 DOI 10.1186/s13643-018-0767-9.

Nelson MC, Kocos R, Lytle LA, Perry CL. 2009. Understanding the perceived determinants of weight-related behaviors in late adolescence: a qualitative analysis among college youth. Journal of Nutrition Education and Behavior 41(4):287-292 DOI 10.1016/j.jneb.2008.05.005.

Oluyinka S, Endozo A. 2019. Factors affecting physical activity participation among university students. Journal of Social Science Research 14:3161-3170 DOI 10.24297/jssr.v14i0.8142.

Plotnikoff RC, Costigan SA, Williams RL, Hutchesson MJ, Kennedy SG, Robards SL, Allen J, Collins CE, Callister R, Germov J. 2015. Effectiveness of interventions targeting physical activity, nutrition and healthy weight for university and college students: a systematic review and meta-analysis. International Journal of Behavioral Nutrition and Physical Activity 12:45 DOI 10.1186/s12966-015-0203-7.

Peer] reviewing PDF | (2020:01:44961:2:0:NEW 26 May 2020) 
704

705

706

707

708

709

710

711

712

713

714

715

716

717

718

719

720

721

722

723

724

725

726

727

728

729

730

731

732

733

734

735

736

737

738

739

740

741

742

743

744

745

746

Prichard I, Kavanagh E, Mulgrew KE, Lim MSC, Tiggemann M. 2020. The effect of Instagram \#fitspiration images on young women's mood, body image, and exercise behavior. Body Image 33:1-6 DOI 10.1016/j.bodyim.2020.02.002.

Ranasinghe C, Sigera C, Ranasinghe P, Jayawardena R, Ranasinghe ACR , Hills AP, King N. 2016. Physical inactivity among physiotherapy undergraduates: exploring the knowledge practice gap. BMC Sports Science, Medicine and Rehabilitation 8:39 DOI 10.1186/s13102-016-0063-8.

Reiner M, Niermann C, Jekauc D, Woll A. 2013. Long-term health benefits of physical activity - a systematic review of longitudinal studies. BMC Public Health 13:813 DOI 10.1186/1471-2458-13-813.

Rollnick S, Miller WR, Butler CC. 2007. Motivational interviewing in health care: helping patients change behavior. New York, NY: Guildford Press.

Rubak S, Sandbaek A, Lauritzen T, Christensen B. 2005. Motivational interviewing: a systematic review and meta-analysis. British Journal of General Practice 55(513):305312.

Sehgal A. 2018. What role do medical students have in shaping the future of the National Health Service? Medical Teacher 40(1): 101-102 DOI 10.1080/0142159X.2017.1319917.

Shaver ER, McGlumphy KC, Gill AK, Hasson RE. 2019. Application of the Transtheoretical Model to Physical Activity and Exercise Behaviors in African-American Adolescents. American Journal of Health Behavior 43(1): 119-132 DOI:10.5993/AJHB.43.1.10.

Sigmundova D, Chmelik F, Sigmund E, Feltlova D, Fromel K. 2013. Physical activity in the lifestyle of Czech university students: Meeting health recommendations. European Journal of Sport Science 13(6):744-750 DOI 10.1080/17461391.2013.776638.

Suerken CK, Reboussin BA, Egan KL, Sutfin EL, Wagoner KG, Spangler J, Wolfson M. 2016. Marijuana use trajectories and academic outcomes among college students. Drug Alcohol Depend 162:137-45 DOI 10.1016/j.drugalcdep.2016.02.041.

Suner A, Yilmaz Y, Pişkin B. 2019. Mobile learning in dentistry: usage habits, attitudes and perceptions of undergraduate students. PeerJ 7:e7391 DOI 10.7717/peerj.7391.

Telama R, Yang X, Leskinen E, Kankaanpaa A, Hirvensalo M, Tammelin T, Viikari JS, Raitakari OT. 2014. Tracking of physical activity from early childhood through youth into adulthood. Medicine and Science in Sports and Exercise 46:955-962 DOI 10.1249/MSS.0000000000000181.

Thomas AM, Beaudry KM, Gammage KL, Klentrou P, Josse AR. 2019. Physical Activity, Sport Participation, and Perceived Barriers to Engagement in First-Year Canadian University Students. Journal of Physical Activity and Health 16(6):437-446 DOI 10.1123/jpah.2018-0198.

Trueman M, Hartley J. 1996. A comparison between the time-management skills and academic performance of mature and traditional-entry university students. Higher education 32:199215 DOI 10.1007/BF00138396.

Wamamili B, Wallace-Bell M, Richardson A, Grace RC, Coope P. 2019. Cigarette smoking among university students aged 18-24 years in New Zealand: results of the first (baseline) of two national surveys. BMJ Open 9(12):e032590 DOI 10.1136/bmjopen-2019-032590.

Peer] reviewing PDF | (2020:01:44961:2:0:NEW 26 May 2020) 
747 Warburton DE, Nicol CW, Bredin SS. 2006. Health benefits of physical activity: the evidence.

748 Canadian Medical Association Journal 174(6):801-809 DOI 10.1503/cmaj.051351.

749 World Health Organization. 2010. Global Recommendations on Physical Activity for Health.

750 Geneva: WHO Press.

751 World Health Organization. Physical activity 2018. Available at https://www.who.int/news-

$752 \quad \mathrm{room} /$ fact-sheets/detail/physical-activity (accessed 24 May 2020).

753 Zhang J, Brackbill D, Yang S, Becker J, Herbert N, Centola D. 2016. Support or

754

755 competition? How online social networks increase physical activity: A randomized controlled trial. Preventive Medicine Reports 4:453-458 DOI

756 10.1016/j.pmedr.2016.08.008. 
Figure 1

Participants' flowchart - recruitment, choice of intervention group and retention

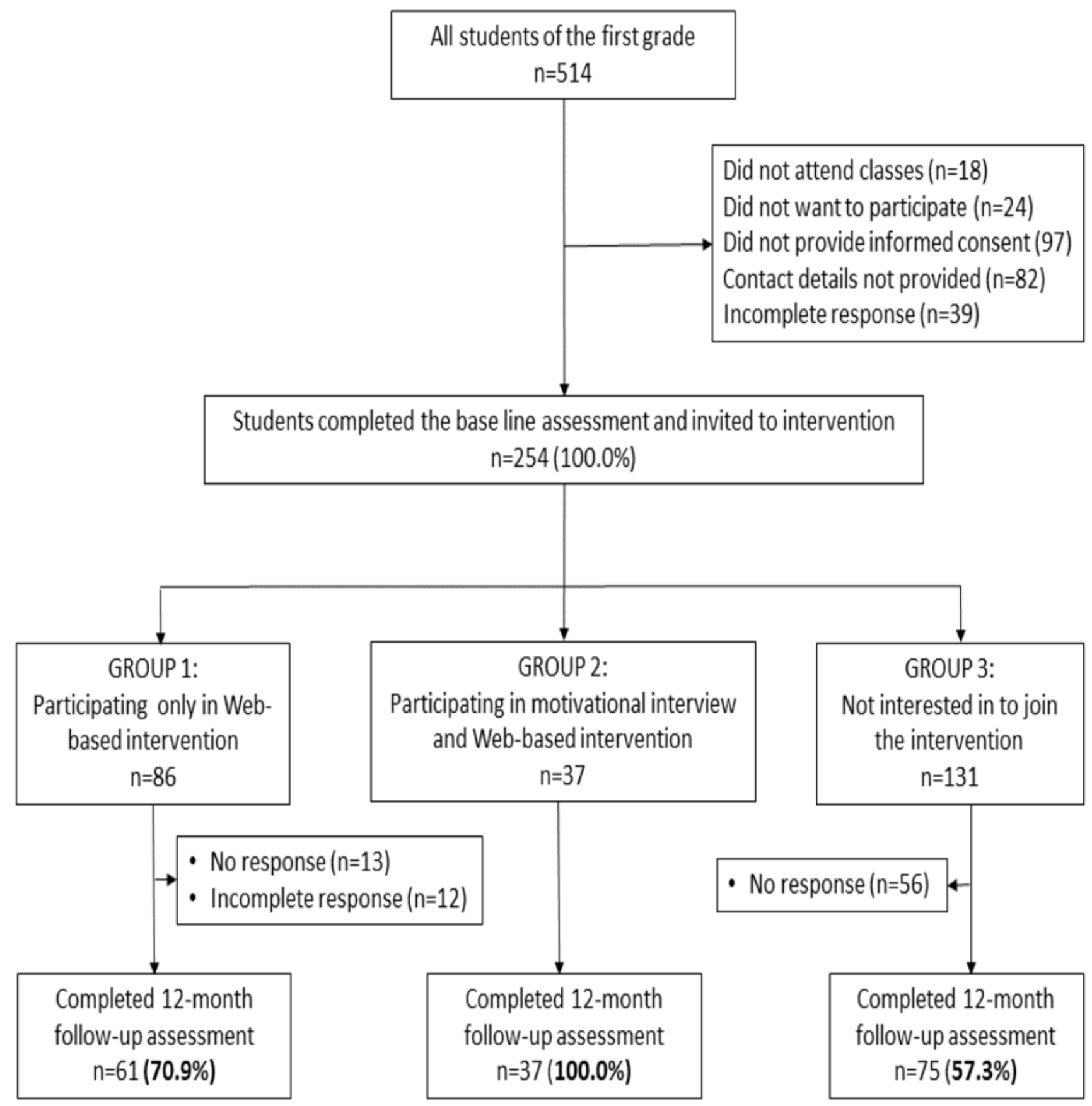


Figure 2

Estimated marginal means of MET before and after the intervention

MET: Metabolic Equivalent of Task

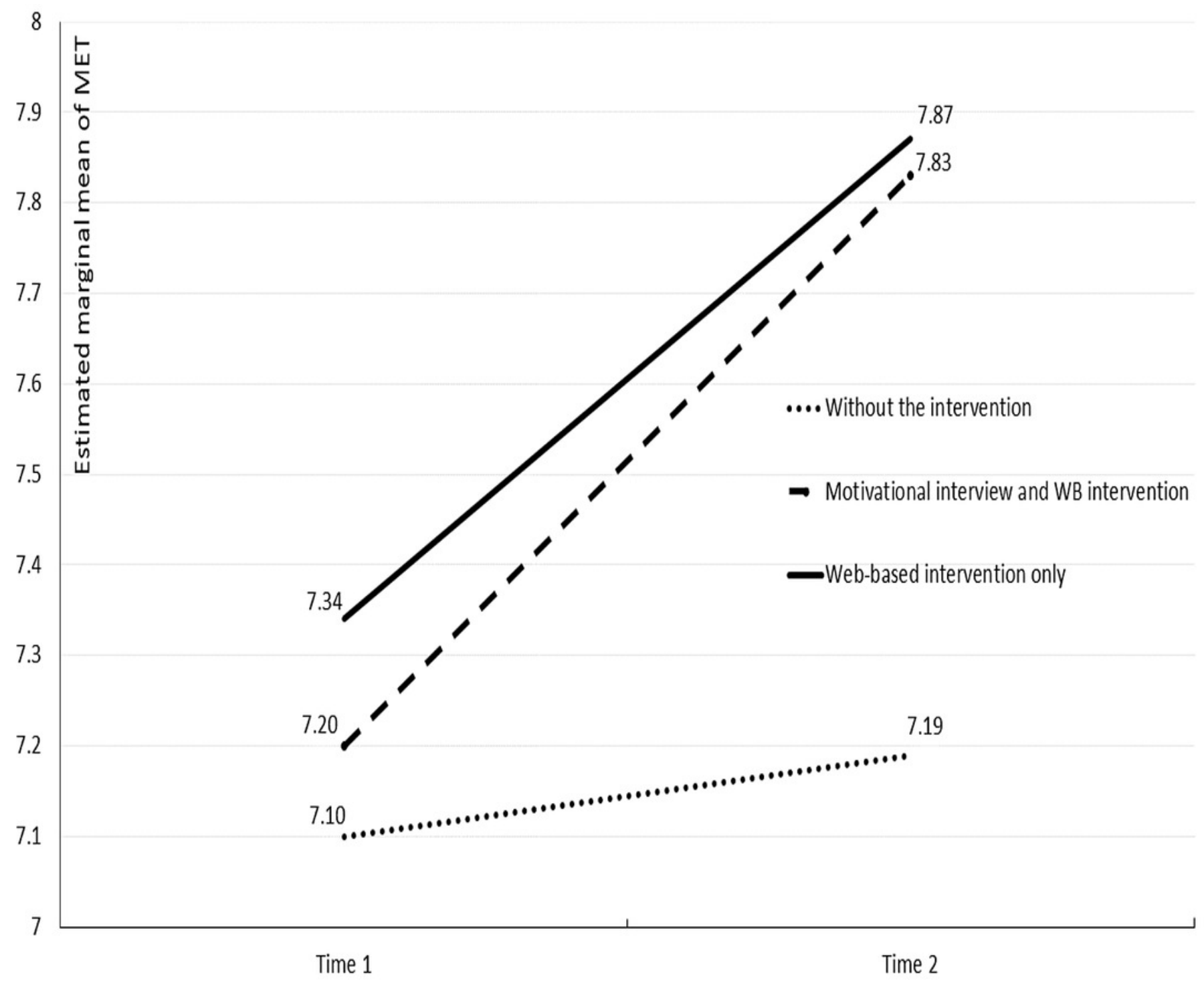




\section{Table 1 (on next page)}

Characteristics of study participants at baseline

Note: Data are presented as n (\%), means \pm standard deviation or median (IQR); not significant (NS) between groups for all parameters. A: Tested by Chi-Square test; B: Tested by One-Way ANOVA; C: Tested by Fisher's Exact test; D: Tested by Kruskal-Wallis test. 


\begin{tabular}{|c|c|c|c|c|c|}
\hline Characteristics & Total & Group 1 & Group 2 & Group 3 & $\mathbf{p}$ \\
\hline Number & $173(100.0 \%)$ & $61(35.3 \%)$ & $37(21.4 \%)$ & $75(43.4 \%)$ & - \\
\hline \multicolumn{6}{|l|}{ Gender ${ }^{A}$} \\
\hline Male, n (\%)/ & $51(29.5 \%) /$ & $14(23.0 \%) /$ & $14(37.8 \%) /$ & $23(30.7 \%) /$ & 0.280 \\
\hline Female, n (\%) & $122(70.5 \%)$ & $47(77.0 \%)$ & $23(62.2 \%)$ & $52(69.3 \%)$ & \\
\hline Age, years $(\mathrm{SD})^{\mathrm{B}}$ & $20.34 \pm 0.57$ & $20.28 \pm 0.52$ & $20.46 \pm 0.69$ & $20.33 \pm 0.55$ & 0.319 \\
\hline $\begin{array}{l}\text { Academic } \\
\text { achievement, average } \\
\text { mark }(\mathrm{SD})^{\mathrm{B}}\end{array}$ & $8.70 \pm 0.80$ & $8.80 \pm 0.79$ & $8.60 \pm 0.71$ & $8.66 \pm 0.84$ & 0.402 \\
\hline \multicolumn{6}{|l|}{$\begin{array}{l}\text { Type of transportation } \\
\text { to the faculty } \mathrm{C}\end{array}$} \\
\hline Walk & $30(17.3 \%)$ & $10(16.4 \%)$ & $9(24.3 \%)$ & $11(14.7 \%)$ & \\
\hline Bicycle & $0(0.0 \%)$ & $0(0.0 \%)$ & $0(0.0 \%)$ & $0(0.0 \%)$ & 0.725 \\
\hline Car & $2(1.2 \%)$ & $1(1.6 \%)$ & $0(0.0 \%)$ & $1(1.3 \%)$ & \\
\hline Public transport & $141(81.5 \%)$ & $50(82.0 \%)$ & $28(75.7 \%)$ & $63(84.0 \%)$ & \\
\hline $\begin{array}{l}\text { Time to get to the } \\
\text { faculty, median (IQR) } \\
\text { D }\end{array}$ & $25(15)$ & $30(13)$ & $20(15)$ & $30(15)$ & 0.103 \\
\hline \multicolumn{6}{|l|}{$\begin{array}{l}\text { Household income per } \\
\text { capita }^{\text {D }}\end{array}$} \\
\hline less than $300 €$ & $52(30.1 \%)$ & $18(29.5 \%)$ & $14(37.8 \%)$ & $20(26.7 \%)$ & \\
\hline $300-400 €$ & $55(31.8 \%)$ & $21(34.4 \%)$ & $8(21.6 \%)$ & $26(34.7 \%)$ & 0.677 \\
\hline $400-500 €$ & $28(16.2 \%)$ & $10(16.4 \%)$ & $8(21.6 \%)$ & $10(13.3 \%)$ & \\
\hline $500-600 €$ & $17(9.8 \%)$ & $4(6.6 \%)$ & $5(13.5 \%)$ & $8(10.7 \%)$ & \\
\hline$>600 €$ & $21(12.1 \%)$ & $8(13.1 \%)$ & $2(5.4 \%)$ & $11(14.7 \%)$ & \\
\hline
\end{tabular}




\section{Table 2 (on next page)}

Health status and life-choices of medical students at baseline

Note: Data are presented as $\mathrm{n}(\%)$ or means \pm standard deviation or means (95Cl intervals); Not significant (NS) between groups for all parameters; A: Tested by Chi-Square test; B: Tested by One-Way ANOVA; C: Tested by Fisher's Exact test; D: Tested by Kruskal-Wallis test. 
1

\begin{tabular}{|c|c|c|c|c|c|}
\hline Characteristics & Total & Group 1 & Group 2 & Group 3 & $\mathbf{p}$ \\
\hline $\begin{array}{l}\text { Number } \\
\text { Self-rated health, n (\%) } \\
\text { D }\end{array}$ & $173(100.0 \%)$ & $61(35.3 \%)$ & $37(21.4 \%)$ & $75(43.4 \%)$ & \\
\hline very good & $81(46.8 \%)$ & $32(52.5 \%)$ & $12(32.4 \%)$ & $37(49.3 \%)$ & \\
\hline good & $68(39.3 \%)$ & $25(41.0 \%)$ & $20(54.1 \%)$ & $23(30.7 \%)$ & 0.168 \\
\hline average & $22(12.7 \%)$ & $3(4.9 \%)$ & $5(13.5 \%)$ & $14(18.7 \%)$ & \\
\hline bad & $1(0.6 \%)$ & $1(1.6 \%)$ & $0(0.0 \%)$ & $0(0.0 \%)$ & \\
\hline very bad & $1(0.6 \%)$ & $0(0.0 \%)$ & $0(0.0 \%)$ & $1(1.3 \%)$ & \\
\hline $\begin{array}{l}\text { Mental health, good } \\
\left(\text { PHQ-8 < 10), n }(\%)^{\mathrm{A}}\right. \\
\text { Body mass measures }^{\mathrm{B}}\end{array}$ & $148(85.5 \%)$ & $55(90.2 \%)$ & $31(83.8 \%)$ & $62(82.7 \%)$ & 0.439 \\
\hline $\begin{array}{l}\text { BMI }\left(\mathrm{kg} / \mathrm{m}^{2}\right) \\
(\mathrm{mean} \pm \mathrm{SD})\end{array}$ & $21.62 \pm 2.75$ & $21.40 \pm 2.37$ & $21.86 \pm 2.70$ & $21.67 \pm 3.06$ & 0.710 \\
\hline $\begin{array}{l}\text { Waist circumference } \\
- \text { male }(\mathrm{cm})(\text { mean } \\
95 \% \mathrm{CI})^{\mathrm{B}}\end{array}$ & $\begin{array}{l}80.5 \\
(78.1-82.9)\end{array}$ & $\begin{array}{l}80.2 \\
(78.8-88.0)\end{array}$ & $\begin{array}{l}79.1 \\
(74.2-86.0)\end{array}$ & $\begin{array}{l}79.1 \\
(75.8-82.4)\end{array}$ & 0.333 \\
\hline $\begin{array}{l}\text { Waist circumference } \\
\text { - female }(\mathrm{cm}) \text { (mean } \\
95 \% \mathrm{CI})^{\mathrm{B}}\end{array}$ & $\begin{array}{l}72.0 \\
(70.46-73.4)\end{array}$ & $\begin{array}{l}73.9 \\
(71.4-76.4)\end{array}$ & $\begin{array}{l}71.3 \\
(68.0-74.6)\end{array}$ & $\begin{array}{l}70.5 \\
(68.7-72.4)\end{array}$ & 0.100 \\
\hline Smoking, $\mathbf{n}(\%)^{\mathrm{A}}$ & $27(15.6 \%)$ & $10(16.4 \%)$ & $7(18.9 \%)$ & $10(13.3 \%)$ & 0.729 \\
\hline $\begin{array}{l}\text { Marijuana use in last } 12 \\
\text { months, } n(\%) \\
\text { Binge drinking in last }\end{array}$ & $9(5.2 \%)$ & $2(3.3 \%)$ & $1(2.7 \%)$ & $6(8.0 \%)$ & 0.447 \\
\hline $\begin{array}{l}12 \text { months, } \mathrm{n}(\%)^{\mathrm{A}} \\
\text { Consumption of fresh }\end{array}$ & $87(50.3 \%)$ & $30(49.2 \%)$ & $17(45.9 \%)$ & $40(53.3 \%)$ & 0.746 \\
\hline fruits daily, n (\%) ${ }^{\mathrm{A}}$ & $60(34.7 \%)$ & $21(34.4 \%)$ & $12(32.4 \%)$ & $27(36.0 \%)$ & 0.936 \\
\hline $\begin{array}{l}\text { Consumption of } \\
\text { vegetables daily }(\%)^{\mathrm{A}}\end{array}$ & $61(35.3 \%)$ & $23(37.7 \%)$ & $14(37.8 \%)$ & $24(32.0 \%)$ & 0.785 \\
\hline
\end{tabular}




\section{Table 3 (on next page)}

The physical activity and related variables before and after intervention

Note: Data are presented as $\mathrm{n}(\%)$, means \pm standard deviation or median (IQR); BL: baseline, 12M: 12 months after intervention; A: Tested by Chi-Square test; B: Tested by OneWay ANOVA; C: Tested by Fisher's Exact test; D: Tested by Kruskal-Wallis test; $p$ BL: p value between Groups 1, 2 and 3 at baseline; p 12M: p value between Groups 1, 2 and 3 after 12 months; ${ }^{*} p<0.001$ vs. starting BL values; Group 1: Web-based intervention only; Group 2: Combined intervention with motivational interview and Web-based intervention; Group 3: without intervention. 


\begin{tabular}{|c|c|c|c|c|c|c|c|c|}
\hline \multirow{2}{*}{ Characteristics } & \multicolumn{2}{|c|}{ Group 1} & \multicolumn{2}{|c|}{ Group 2} & \multicolumn{2}{|c|}{ Group 3} & \multirow{2}{*}{ p BL } & \multirow{2}{*}{ p $12 \mathrm{M}$} \\
\hline & BL & $12 \mathrm{M}$ & BL & $12 \mathrm{M}$ & BL & $12 \mathrm{M}$ & & \\
\hline $\begin{array}{l}\text { Physical activity, } \\
\text { median MET (IQR) }\end{array}$ & $1506(2058)$ & $2813(1680)^{*}$ & $1386(1579)$ & $2586(1794)^{*}$ & $1155(1053)$ & $1222(1253)$ & $0.398^{\mathrm{D}}$ & $\mathrm{p}<0.001^{\mathrm{D}}$ \\
\hline $\begin{array}{l}\text { Total number of } \\
\text { reasons for inactivity } \\
(\text { mean } \pm \text { SD) }\end{array}$ & $1.16 \pm 0.68$ & $1.05 \pm 1.04$ & $1.54 \pm 1.00$ & $1.22 \pm 0.88$ & $1.21 \pm 0.87$ & $1.17 \pm 1.05$ & $0.292^{\text {в }}$ & $0.399^{\text {в }}$ \\
\hline \multicolumn{9}{|l|}{$\begin{array}{l}\text { Reasons for } \\
\text { inactivity, n (\%) }\end{array}$} \\
\hline no time & $43(70.5 \%)$ & $34(55.7 \%)$ & $30(81.1 \%)$ & $26(70.3 \%)$ & $53(70.7 \%)$ & $44(58.7 \%)$ & $0.445^{\mathrm{A}}$ & $0.342^{\mathrm{A}}$ \\
\hline too tired & $25(41.0 \%)$ & $17(27.9 \%)$ & $14(37.8 \%)$ & $8(21.6 \%)$ & $21(28.0 \%)$ & $16(21.3 \%)$ & $0.258^{\mathrm{A}}$ & $0.635^{\mathrm{A}}$ \\
\hline no wish & $1(1.6 \%)$ & $8(13.1 \%)$ & $7(18.9 \%)$ & $8(21.6 \%)$ & $11(14.7 \%)$ & $18(24.0 \%)$ & $0.012^{\mathrm{A}}$ & $0.267^{\mathrm{A}}$ \\
\hline do not like & $1(1.6 \%)$ & $2(3.3 \%)$ & $2(5.4 \%)$ & $2(5.4 \%)$ & $3(4.0 \%)$ & $6(8.0 \%)$ & $0.658^{\mathrm{C}}$ & $0.491^{\mathrm{C}}$ \\
\hline other & $1(1.6 \%)$ & $3(4.9 \%)$ & $4(10.8 \%)$ & $1(2.7 \%)$ & $3(4.0 \%)$ & $4(5.3 \%)$ & $0.100^{\mathrm{C}}$ & $1.000^{\mathrm{C}}$ \\
\hline $\begin{array}{l}\text { Total number of } \\
\text { preferred activities } \\
(\text { mean } \pm \text { SD) }\end{array}$ & $2.39 \pm 1.26$ & $2.68 \pm 1.48$ & $2.57 \pm 1.25$ & $2.97 \pm 1.23$ & $1.92 \pm 1.1$ & $2.79 \pm 1.49$ & $0.010^{\mathrm{B}}$ & $0.371^{\text {в }}$ \\
\hline \multicolumn{9}{|l|}{$\begin{array}{l}\text { Type of preferred } \\
\text { physical activity, n } \\
(\%)\end{array}$} \\
\hline Walk & $34(55.7 \%)$ & $37(60.7 \%)$ & $24(64.9 \%)$ & $32(86.5 \%)$ & $35(46.7 \%)$ & $54(72.0 \%)$ & $0.182^{\mathrm{A}}$ & $0.023^{\mathrm{A}}$ \\
\hline Jogging & $18(29.5 \%)$ & $25(41.0 \%)$ & $12(32.4 \%)$ & $16(43.2 \%)$ & $18(24.0 \%)$ & $28(37.3 \%)$ & $0.599^{\mathrm{A}}$ & $0.815^{\mathrm{A}}$ \\
\hline Individual gym & $15(24.6 \%)$ & $25(41.0 \%)$ & $8(21.6 \%)$ & $13(35.1 \%)$ & $12(16.0 \%)$ & $26(34.7 \%)$ & $0.451^{\mathrm{A}}$ & $0.724^{\mathrm{A}}$ \\
\hline Group gym & $12(19.7 \%)$ & $14(23.00 \%)$ & $8(21.6 \%)$ & $3(8.1 \%)$ & $8(10.7 \%)$ & $18(24.0 \%)$ & $0.219^{\mathrm{A}}$ & $0.116^{\mathrm{A}}$ \\
\hline Group sports & $17(27.9 \%)$ & $18(29.5 \%)$ & $7(18.9 \%)$ & $14(37.8 \%)$ & $18(24.0 \%)$ & $25(33.3 \%)$ & $0.604^{\mathrm{A}}$ & $0.693^{\mathrm{A}}$ \\
\hline Swimming & $18(29.5 \%)$ & $21(34.4 \%)$ & $17(45.9 \%)$ & $19(51.4 \%)$ & $20(26.7 \%)$ & $23(30.7 \%)$ & $0.107^{\mathrm{A}}$ & $0.094^{\mathrm{A}}$ \\
\hline Skiing & $13(21.3 \%)$ & $8(13.1 \%)$ & $8(21.6 \$)$ & $4(10.8 \%)$ & $16(21.3 \%)$ & $11(14.7 \%)$ & $0.999^{\mathrm{A}}$ & $0.851^{\mathrm{A}}$ \\
\hline Dance & $17(27.9 \%)$ & $11(18.0 \%)$ & $10(27.0 \%)$ & $9(24.3 \%)$ & $14(18.7 \%)$ & $14(18.7 \%)$ & $0.394^{\mathrm{A}}$ & $0.719^{\mathrm{A}}$ \\
\hline Other & $2(3.3 \%)$ & $5(8.2 \%)$ & $1(2.7 \%)$ & $0(0.0 \%)$ & $3(4.0 \%)$ & $10(13.3 \%)$ & $1.000^{\mathrm{C}}$ & $0.061^{\mathrm{A}}$ \\
\hline $\begin{array}{l}\text { Total number of } \\
\text { planned activities } \\
(\text { mean } \pm \text { SD) }\end{array}$ & $1.61 \pm 0.93$ & $1.89 \pm 1.05$ & $1.89 \pm 0.85$ & $2.32 \pm 1.31$ & $1.51 \pm 0.86$ & $2.04 \pm 0.97$ & $0.079^{\text {в }}$ & $0.244^{\text {в }}$ \\
\hline $\begin{array}{l}\text { Wish for physical } \\
\text { activity, n (\%) }\end{array}$ & $58(95.1 \%)$ & $53(86.9 \%)$ & $35(94.6 \%)$ & $36(97.3 \%)$ & $69(92.0 \%)$ & 67 (89.3\%) & $0.855^{\mathrm{C}}$ & $0.232^{\mathrm{A}}$ \\
\hline $\begin{array}{l}\text { Satisfaction with } \\
\text { physical activity, n } \\
(\%)\end{array}$ & $9(14.8 \%)$ & $25(41.0 \%)$ & $4(10.8 \%)$ & $10(27.0 \%)$ & $13(17.3 \%)$ & $23(30.7 \%)$ & $0.660^{\mathrm{A}}$ & $0.287^{\mathrm{A}}$ \\
\hline
\end{tabular}




\section{Table 4 (on next page)}

Logistic regression identifying associations between physical activity with type of intervention and other physical activity related variables

Note: a. Variable(s) entered on step 1: Type of intervention, Total number of reasons BL, Satisfaction with physical activity BL, Wish for physical activity BL, Total number of preferred activities BL, Total number of planned activities BL., BL - baseline, WB - Web-based intervention. 
2

\begin{tabular}{|c|c|c|c|c|c|c|c|c|}
\hline \multirow{2}{*}{ Variables } & \multirow{2}{*}{ B } & \multirow{2}{*}{ S.E. } & \multirow{2}{*}{ Wald } & \multirow{2}{*}{ df } & \multirow{2}{*}{ Sig. } & \multirow{2}{*}{$\operatorname{Exp}(B)$} & \multicolumn{2}{|c|}{$95 \%$ CI for $\operatorname{Exp}(B)$} \\
\hline & & & & & & & Lower & Upper \\
\hline Type of intervention & & & 19.581 & 2 & 0.000 & & & \\
\hline $\begin{array}{l}\text { Motivational interview } \\
\text { and WB intervention }\end{array}$ & 1.171 & 0.694 & 2.848 & 1 & 0.091 & 3.225 & 0.828 & 12.561 \\
\hline Without intervention & -1.344 & 0.410 & 10.741 & 1 & 0.001 & 0.261 & 0.117 & 0.583 \\
\hline $\begin{array}{l}\text { Total number of reasons } \\
\text { for inactivity } B L\end{array}$ & 0.704 & 0.318 & 4.894 & 1 & 0.027 & 2.022 & 1.084 & 3.772 \\
\hline $\begin{array}{l}\text { Satisfaction with physical } \\
\text { activity BL (coded } 1 \text { - } \\
\text { No) }\end{array}$ & -0.428 & 0.627 & 0.467 & 1 & 0.494 & 0.652 & 0.191 & 2.226 \\
\hline $\begin{array}{l}\text { Wish for physical activity } \\
\text { BL( coded } 1 \text { - yes) }\end{array}$ & 0.928 & 0.746 & 1.547 & 1 & 0.214 & 2.528 & 0.586 & 10.906 \\
\hline $\begin{array}{l}\text { Total number of } \\
\text { preferred activities BL }\end{array}$ & -0.198 & 0.183 & 1.163 & 1 & 0.281 & 0.821 & 0.573 & 1.175 \\
\hline $\begin{array}{l}\text { Total number of planned } \\
\text { activities BL }\end{array}$ & -0.140 & 0.247 & 0.324 & 1 & 0.569 & 0.869 & 0.536 & 1.409 \\
\hline Constant & .619 & 0.833 & 0.552 & 1 & 0.458 & 1.856 & & \\
\hline
\end{tabular}

